\title{
Analysis of Effectiveness of the Social-Pedagogical Leisure Activities System for Formation of Student Youth's Social Activity
}

\author{
Nataliia Viacheslavivna Shepelieva
}

\author{
Postgraduate Student, \\ Kharkiv State Academy of Culture, \\ Kharkiv, Ukraine
}

\section{Nataliia Oleksandrivna Maksymovska}

Doctor of Pedagogical Sciences,

Kharkiv State Academy of Culture,

Kharkiv, Ukraine

\section{Angela Oleksandrivna Polyanichko}

Candidate of Pedagogic Sciences, Sumy State Pedagogical University named after A.S. Makarenko, Sumy, Ukraine

DOI: https://doi.org/10.36941/jesr-2020-0o84

\section{Abstract}

\begin{abstract}
Formation of student youth's social activity is the leading task of social education, especially under conditions of information society. If psychological and age traits of students as a social group are to be taken into account, the beneficial means of harmonizing this process is leisure activities. Based on interdisciplinary and integrated approaches, a system of social-pedagogical leisure activities was developed to form social activity of student youth. The aim of this article is to analyze the implementation of the social-pedagogical leisure activities system of student youth's social activity formation. The task of this article is to study the levels of student youth's social activity before and after implementing the social-pedagogical leisure activities system and to analyze its effectiveness using the corresponding methods. According to outlined tasks, the following methods and indices were selected and used: relative indices method, grouping method, quantitative and qualitative analysis method, Student's t-test, graphical method. Thanks to systematic approach to experimental part of the research, it was established that the level of students' social activity formation has improved: the specific share of young people with low level has decreased significantly, while of those with high level has increased. Group curators have noted the tendencies of young people to organize leisure activities, while students themselves were becoming involved in useful leisure practices that were new to them. Effectiveness of the new system was confirmed using statistical methods.
\end{abstract}

Keywords: student youth's social activity formation, leisure activities, social-pedagogical leisure activities system

\section{Introduction}

The issue of forming student youth's social activity and the importance of manifesting it is determined by the global nature of advancement and attempts at solving it. Based on worldwide 
practice, it is important to note that at the end of the previous century a World Declaration on Higher Education for the Twenty-First Century (World Declaration on Higher Education for the Twenty-first Century: Vision and Action) was passed, which defines value orientations in teaching and education. For us, an important statement is: "to provide opportunity for individual development and social mobility in order to nurture the spirit of civility, as well as to create endogenous potential and reinforce human rights, steady development, democracy and peace in the spirit of justice" (World Declaration on Higher Education for the Twenty-First Century: Vision and Action and Frame-work For Priority Action for Change and Development in Higher Education, 1998). This reflects the aim of forming students' social activity, which lies in development of socially responsible youth, capable of positive initiatives, which are important for society. It is especially significant under conditions of information society, which transforms the daily life of young people. For instance, the following issues were added to traditional issues of student youth (financial insolvency, political instability, electoral incompetence, social vulnerability etc.) (Bogdanova, 20o8; Zvereva, 1998; Smuk\&Kozubovsky, 2014): diving into virtual world, computer loneliness and virtual isolation, information pileup and apathetication, development of consumerism, virtual crimes and Internet fraudulence etc. (Voronkova, 2017; Prokhorenko, 2016). The tendency for accelerated development of society requires implementation of social-pedagogical approach to increase students' pro-social initiativity under conditions of contemporary challenges. That is why social-pedagogical work with student youth in a higher education institution (henceforward - HEI) and beyond becomes significant as optimal by psychological and age traits of a social group, which becomes responsible for solving intersocial issues of society. Taking into account the main types of students' activities and lack of adequate investigation of the issue of social activity formation, development of socialpedagogical leisure activities system for formation of student youth's social activity is a priority direction.

\section{Literature Review}

Among the latest research regarding formation of student youth's social activity, works by O. Aseeva, O. Kulinichenko and E. Shakirova should be highlighted, which, as we believe, create the basis for contemporary empirical knowledge on the issue that is being investigated. E. Shakirova has pinpointed the issue of forming students' social activity in 2010 (thesis research "Forming social activity of teachers college students in extracurricular activities") (Shakirova, 2010), developing personal methodology for analyzing formation of student youth's social activity. This methodology is being used by scientists even today, as it allows to bring out the development tendencies of social activity components that are inherent to students. Taking into account the fact that the research was conducted only among the students of the teachers college, whose education process is more guided by social-pedagogical tools, based on calculations by E. Shakirova (2008) we found that students in general are positively directed, possess important socially-significant qualities, however they are focused on themselves (personal well-being, profit, consumerism). The scientist emphasizes the necessity of developing such traits as being organized, diligence and initiativity, which are important components for forming student youth's social activity, and proposes to do this during extracurricular hours (Shakirova, 2008).

O. Kulinichenko follows the scientific thoughts of E. Shakirova, who, based on methodology and results of his predecessor's research, has researched the available level of student youth's maturity and proposed a program to improve it (thesis research "Formation of students' social activity under conditions of self-government authorities' activities at a higher education institution", 2015) (Kulinchenko, 2015). Researcher had conducted a two-step ascertaining experiment: defining a list of qualities that characterize a student as a socially active person, defining the levels of maturity of students' social activity. According to part one, student youth understands the nature of a defined issue fragmentarily and subconsciously notes the low level of their own social activity's formation, which is confirmed by their answers to questions regarding qualities that they lack: integrity, 
tolerance, sense of justice, sociability and self-organization. This confirmed the results of the second step of O. Kulinichenko's ascertaining experiment (2005), which allowed to define that most students are not particularly well-developed in terms of meaningful qualities and assume a stance of adaptation to fickle conditions of daily life (p.13).

Taking into account contemporary society's development conditions, O. Aseeva researched the influence of Internet on students' social activity (thesis research "Virtualization of youth's social activity in network communities", 2015) (Aseeva, 2015). The researcher (2015) notes that capabilities and advantages of virtual space are usually used by most students for entertainment (Internetsurfing, social networks, listening and watching audio and video content etc.) (p. 89), which not only slows down formation of social activity, but also generally decreases it. As such, most young people are simply "killing time" (p. 72, p. 95), thus developing addiction to Internet (Aseeva, 2015).

Abovementioned facts allow us to conclude that the issue of forming student youth's social activity is a major one - most students do not possess enough social activity, while underexamination of the issue requires substantial social-pedagogical research.

\section{Aim and Tasks}

The aim of this article is to analyze the implementation of social-pedagogical activity system for formation of student youth's social activity. The tasks we have designated are to study the formation levels of student youth's social activity before and after implementing the social-pedagogical leisure activities system and to analyze its effectiveness using the corresponding methods.

\section{Research Methodology}

Four HEIs were selected for the experiment: Kharkiv State Academy of Culture (henceforward KhSAC), Kharkiv National University of Arts named after I. P. Kotlyarevsky (henceforward - KhNUA n. a. I. P. Kotlyarevsky), Sumy State Pedagogical University named after A. S. Makarenko (henceforward - SumSPU n. a. A. S. Makarenko), Kharkiv University of Humanities "People's Ukrainian Academy" (henceforward - KUH "PUA"), which match the research conditions (complementarity and comparability of HEIs and selected student groups; common educational direction of HEIs; presence and cooperation with academic group curators; geographical setting of HEIs within a single region of the state). 1200 students were involved in the study: 300 persons from SumSPU n. a. A. S. Makarenko; 302 persons from KUH "PUA"; 292 persons from KhSAC; 306 persons from KhNUA n. a. I. P. Kotlyarevsky.

The following methodologies were selected and used for diagnostics: determining person's life values (Must-test) (P. Ivanov, E. Kolobova); self-evaluation of psychological adaptability; determining person's social creativity; diagnostics of leadership abilities (E. Zharikov, E. Krushelnitskyi); studying the ability to self-control in conversation; self-evaluation of person's creative potential; diagnostics of communicative and organizational inclinations (COI-2); diagnostics of perceptive-interactive competence (modified variant by M. Fetiskin); evaluation of person's creative potential level; author's feedback form "Formation of student youth's social activity in leisure activities".

To analyze the results, the following methods and indices were used: relative indices method, grouping method, quantitative and qualitative analysis method, Student's t-test, graphical method.

\section{Analysis of Results and Discussions}

Because we view student youth's social activity from the social-pedagogical point, we see it as a social quality, which is a component of students' sociality, characterized by gaining civic and professional values, development of characteristic qualities (initiativity, social mobility, social creativity) based on them, which manifest in pro-social behavior and are simultaneously both a condition and a result of educational, extracurricular, civic activities during education at a higher education institution and 
beyond it in all fields of society's daily life.

Sociality development criteria by O. Bilyk (Bilyk, 2018), N. Maksymovska (Maksimovska, 2015), M. Maksymovskyi (Maksimovsky, 2018), O. Rasskazova (Rasskazova, 2014), A. Tadaeva (Tadaeva, 2016), O. Hendryk (Hendrick, 2014) and others act as a basis for defining the criteria of student youth's social activity, analysis of which allows us to single out the following: motivation-value, reflection-will, activity. Each of them are evaluated by indices that reflect the nature of the term "student youth's social activity". Among the indices we distinguish: initiativity, social mobility, social creativity. Depending on the level of development of social activity by every index, we distinguish the following levels of student youth's social activity: high, medium, low.

Taking into account scientific developments that were analyzed and the contents of students' social activity, we see formation of student youth's social activity as regulated social-pedagogical process of facilitating internalization of civic and professional values by students, gaining and manifesting pro-social behavior based on initiativity, social mobility and social creativity both under conditions of HEI and in open social environment of the information age.

Theoretical justification of the issue of forming students' social activity increases the importance of organizing and realizing the experimental part of the research, which consists of the following stages: diagnostics, formation, control.

Diagnostics stage stipulated defining the level of formation of student youth's social activity using response analysis for the selected methodologies. Using relative indices method, grouping and quantitative-qualitative analysis, we have defined the levels of formation of students' social activity in selected HEIs (table 1).

Table 1: Results of calculating the "formation of social activity" index of student youth at the diagnostics stage of the experiment, $\%$

\begin{tabular}{|l|c|c|c|}
\hline \multirow{2}{*}{ Groups } & \multicolumn{3}{|c|}{ Levels of formation of student youth's social activity } \\
\cline { 2 - 4 } & high & medium & low \\
\hline KhSAC & $\mathbf{2 1 . 5 3}$ & 39.09 & 39.38 \\
\hline SumSPU n. a. A. S. Makarenko & 21.59 & 38.95 & 39.46 \\
\hline KhNUA n. a. I. P. Kotlyarevsky & $\mathbf{2 2 . 1 1}$ & 39.98 & 37.91 \\
\hline KUH “PUA" & $\mathbf{2 2 . 6 7}$ & 40.37 & 36.96 \\
\hline
\end{tabular}

From obtained results, the following tendencies were uncovered:

- approximately $1 / 5$ of students questioned (KhSAC $-21.53 \%$, SumSPU n. a. A. S. Makarenko $21.59 \%$, KhNUA n. a. I. P. Kotlyarevsky - 22.11\%, KUH "PUA" - 40.37\%) are at the high level of formation of social activity;

- most students questioned possess medium level of formation of social activity (KhSAC $39.09 \%$, SumSPU n. a. A. S. Makarenko - 38.95\%, KhNUA n. a. I. P. Kotlyarevsky - 39.09\%, KUH "PUA" - 40.37\%);

- more than a third of students questioned are at the low level of formation of students' social activity (KhSAC - 39.38\%, SumSPU n. a. A. S. Makarenko - 39.46\%, KhNUA n. a. I. P. Kotlyarevsky - 37.91\%, KUH "PUA" - 36.96\%).

Results of diagnostics allow us to distinguish two groups of students, who possess the best level of formation of students' social activity - students of KhNUA n. a. I. P. Kotlyarevsky and KUH "PUA". We assume that this fact is related to degree of organization of students' extracurricular activities, which influences formation of social activity. In relation to this, experimental (with lower social activity level) and control groups (with higher social activity level) have been defined:

EG 1 - KhSAC students,

EG 2 - SumSPU n. a. A. S. Makarenko students;

CG 1 - KhNUA n. a. I. P. Kotlyarevsky students;

CG 2 - KUH "PUA" students. 
The social-pedagogical leisure activities system for formation of student youth's social activity was realized with experimental groups' students, the aim was to stimulate development of medium and low levels of formation of student youth's social activity.

Formation stage stipulates development and implementation of the social-pedagogical leisure activities system for formation of student youth's social activity for experimental groups' students in order to increase its level. As R. Hanmurzina notes, due to "the absence of the necessary experience of mastering subjective culture-leisure activities, limitation of general culture and narrowness of mental interests, forms of social activity that are being selected are far from constructive" (Hanmurzina, 2013). That is why the social-pedagogical leisure activities system we developed constitutes a regulated planning and organization process for a complex of leisure practices, which is based on the foundations of social-pedagogical technologies. Additionally, it is important to take into account the characteristic features of information society and its influence on the development of student's personality and formation of their social activity, as well as transformation of leisure activities of young people.

Among the main leisure events realized with student youth at every sublevel of formation of social activity (individual, group, extracurricular-leisure of HEI, open leisure environment), the following leisure practices were realized:

$>$ at the individual level: training session on the topic "Me and society", online testing to verify information awareness and literacy, online-quest on the topic "I am a cyber-student", creative studies with various directions (making healthy sweets as part of "Healthy week" promotional campaign, editing and arranging musical compositions and performances, building bird feeding spots and houses for homeless animals etc.), holding a presentation on the topic "The most popular and free kinds of leisure practices in large cities of Ukraine Kharkiv, Kyiv, Odesa, Lviv";

$>$ at the group level: a trip to Kharkiv State Scientific Library n. a. V. H. Korolenko, organizing celebratory performances for children on New Year and Christmas festivities, photo exhibition "Path to dream", participating in XIXth All-Ukrainian radio dictation for national unity, organizing social promotion campaign "We win together", which was dedicated to worldwide AIDS prevention day, organizing voluntary movement "Плог.Kh", the aim of which is to protect and preserve the ecological system;

$>$ at the level of extracurricular-leisure of HEI: organizing student methodological board "Improving the organization of students' leisure activities", interactive debate evening on the topic "What depends on me in life?", student project contest on the topic "We can do better", thematic evening "Virtual reality", viewing and discussing the corresponding footage;

$>$ open leisure environment level: creating students' forum “ХДАК.Інфо” and “Мистецтва News" in mobile apps, organizing a social promotion campaign "Cup of coffee" in social networks, which is aimed at collecting funds to help homeless animals, creating leisure services virtual centre "Virtual galleries" using a YouTube-channel, which is aimed at informing and promoting local tourism by creating short video sessions of informational and educational nature on a chosen topic, virtual leisure environment "Not a boring quarantine" on the Google Class platform.

Thanks to organization and implementation of such multidirectional leisure practices, which are stipulated by social-pedagogical leisure activities system of formation of student youth's social activity, students:

- direct their potential in a positive direction thanks to organization of leisure activities in terms of social-pedagogical approach;

- develop socially significant qualities: tolerance, self-starting, motivation, positive determination, social responsibility, educational activity, social mobility etc.;

- obtain socially-useful activity habits in both real and virtual environments, which is a 
necessary requirement for contemporary daily life of a socially active young person.

Control stage of the experimental part of the research stipulates verification of efficacy of the social-pedagogical leisure activities system and reaching its general aim. Diagnostic and questioning methodologies were used again to compare results before and after implementing the events of social-pedagogical leisure activities system of formation of student youth's social activity. Results of calculations are presented in table 2 and figure 2.

Table 2: Reduced comparative results of calculating the "formation of social activity" index for student youth in experimental and control groups at the beginning and after realizing the socialpedagogical leisure activities system of formation of student youth's social activity, \%

\begin{tabular}{|l|c|c|c|c|c|c|}
\hline \multirow{2}{*}{ Groups } & \multicolumn{6}{|c|}{ Student youth's social activity levels } \\
\cline { 2 - 7 } & \multicolumn{3}{|c|}{ Before the experiment } & \multicolumn{3}{c|}{ After the experiment } \\
\cline { 2 - 7 } & high & medium & low & high & medium & low \\
\hline EG 1 & 21.53 & 39.09 & 39.38 & 28.05 & 50.42 & 21.53 \\
\hline EG 2 & 21.59 & 38.95 & 39.46 & 28.13 & 51.04 & 20.83 \\
\hline CG 1 & 22.11 & 39.98 & 37.91 & 22.97 & 41.06 & 35.97 \\
\hline CG 2 & 22.68 & 40.37 & 36.96 & 23.60 & 41.50 & 34.90 \\
\hline
\end{tabular}

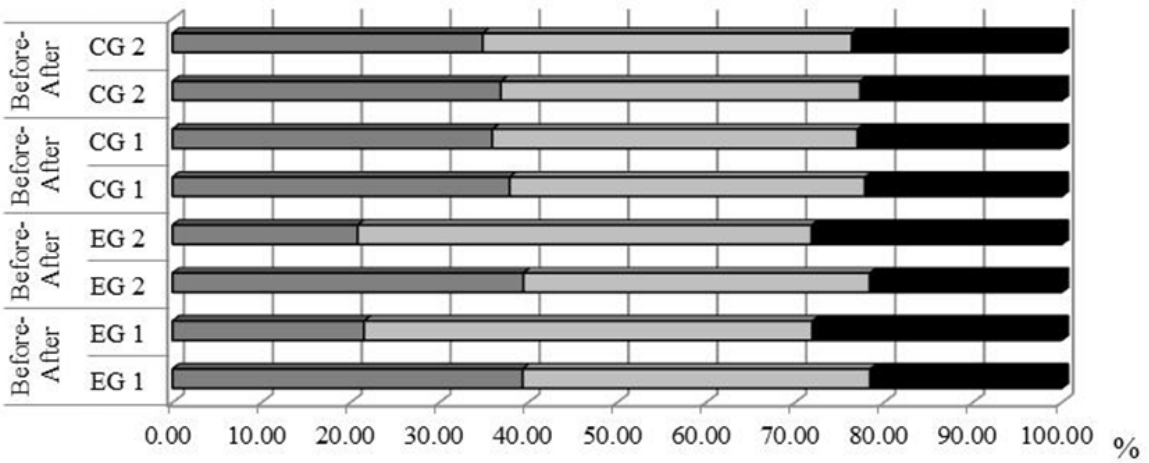

$\square$ low $\square$ medium ahigh

Figure. 2. Result of calculating the general index of student youth's "formation of social activity" in experimental (EG 1, EG 2) and control (CG 1, CG 2) groups before and after realizing the socialpedagogical leisure activities system of formation of student youth's social activity, \%

In general, when comparing the results of the index "formation of social activity" of students before and after realizing the social-pedagogical leisure activities system (table 2), it is possible to say that its level increased thanks to improvement of constituent indexes (self-starter, social mobility, social creativity) by all criteria (motivation-value, reflection-will, activity) in the following way:

- specific share of EG 1 students with low level of social activity formation decreased by 17.84 percentage points (henceforward - p. p.)., with medium level - increased by 11.33 p. p., with high level - increased by 6.52 p. p., which in percentage correlation constitutes $\Delta=-45.31 \%$, $\Delta=+29.00 \%, \Delta=+30.26 \%$ respectively;

- $\quad$ specific share of EG 2 students with low level of social activity formation decreased by 18.63 p. p., with medium level - increased by 12.09 p. p., with high level - increased by 6.54 p. p., which in percentage correlation constitutes $\Delta=-47.22 \%, \Delta=+31.05 \%, \Delta=+30.31 \%$ respectively; 
- specific share of CG 1 students with low level of social activity formation decreased by 1.94 p. p., with medium level - increased by 1.08 p. p., with high level - increased by 0.86 p. p., which in percentage correlation constitutes $\Delta=-5.13 \%, \Delta=+2.71 \%, \Delta=+3.89 \%$ respectively;

- specific share of CG 2 students with low level of social activity formation decreased by 2.06 p. p., with medium level - increased by 1.13 p. p., with high level - increased by 0.92 p. p., which in percentage correlation constitutes $\Delta=-5.57 \%, \Delta=+2.81 \%, \Delta=+4.07 \%$ respectively.

In order to verify the effectiveness of the developed social-pedagogical leisure activities system of formation of student youth's social activity, a Student's t-test statistical calculation method was selected. First of all, two contrary hypotheses were formed:

hypothesis o - social-pedagogical leisure activities system of formation of student youth's social activity facilitates the decrease of specific share of students with low level of formation of student youth's social activity and improves its development to medium and high levels, which confirms the effectiveness of the developed system (meaning that separation rows are significantly different by results obtained before conducting the experiment compared to after it);

hypothesis 1 - social-pedagogical leisure activities system for formation of student youth's social activity does not influence the level of students' social activity formation, which speaks about inefficiency of implemented events of the developed system (meaning that separation rows are almost identical by results before conducting the experiment and after it).

Student's t-test is used to define statistical significance of differences of mean values of two totalities and is calculated via the following formula:

$\mathrm{t}=\frac{\mathrm{M}_{1}-\mathrm{M}_{2}}{\sqrt{\mathrm{m}_{1}^{2}+\mathrm{m}_{2}^{2}}}$

where $\mathrm{M}_{1}$ is the arithmetical mean of the first group that is being compared;

$\mathrm{M}_{2}$ is the arithmetical mean of another group that is being compared;

$\mathrm{m}_{1}$ is the mean error of arithmetical mean of the first group that is being compared;

$\mathrm{m}_{2}$ is the mean error of arithmetical mean of the second group that is being compared.

In order to realize Student's t-test calculation, we used STATISTICA software. The following results were obtained (figure 3 ):

\begin{tabular}{|c|c|c|c|c|c|c|}
\hline \multirow[b]{2}{*}{ Group 1 vs. Group 2} & \multicolumn{6}{|c|}{$\begin{array}{l}\text { T-test for Independent Samples (Spreadsheet } 1 \text { ) } \\
\text { Note: Variables were treated as independent samples }\end{array}$} \\
\hline & \begin{tabular}{|c|} 
Mean \\
Group 1
\end{tabular} & $\begin{array}{l}\text { Mean } \\
\text { Group 2 }\end{array}$ & t-value & $\mathrm{df}$ & $p$ & $\begin{array}{l}\text { Valid N } \\
\text { Group } 1\end{array}$ \\
\hline EG 1, EG 2 vs. CG 1, CG 2 & 1,931438 & 2,122924 & $-4,54801$ & 1198 & 0,000006 & 598 \\
\hline
\end{tabular}

\begin{tabular}{|c|c|c|c|c|c|}
\hline \multirow[b]{2}{*}{ Group 1 vs. Group 2} & \multicolumn{5}{|c|}{$\begin{array}{l}\text { T-test for Independent Samples (Spreadsheet1) } \\
\text { Note: Variables were treated as independent samples }\end{array}$} \\
\hline & $\begin{array}{l}\text { Valid N } \\
\text { Group } 2\end{array}$ & $\begin{array}{l}\text { Std.Dev. } \\
\text { Group } 1\end{array}$ & $\begin{array}{l}\text { Std.Dev. } \\
\text { Group } 2\end{array}$ & $\begin{array}{c}\text { F-ratio } \\
\text { Variances }\end{array}$ & $\begin{array}{c}\mathrm{p} \\
\text { Variances }\end{array}$ \\
\hline EG 1, EG 2 vs. CG 1, CG 2 & 602 & 0,699592 & 0,757551 & 1,172557 & 0,051668 \\
\hline
\end{tabular}

Figure 3. STATISTICA interactive window: results of calculating Student's t-test

Figure 3 presents the following intermediate and final indexes for calculating Student's t-test:

- Mean Group - mean variable values by groups, where group 1 - EG 1 and EG 2, group 2 - CG 1 and CG 2, equal to 1.93 and 2.12 respectively;

- Valid N Group - number of observations in the group, that is group length, which constitutes 598 students for group 1 (EG 1 and EG 2), and 602 students for group 2 (CG 1 and CG 2);

- Std. Dev. Group - standard variable value deviation, which for group 1 (EG 1 and EG 2) equals 0.69 , and for group 2 (CG 1 and CG 2) - 0.76, which indicates lower social activity formation level in group 2 compared to group 1 ; 
- F-ratio Variance - dispersion test, which equals 1.17;

- p Variances -F-ratio significance level - dispersion test, which is equal to 0.051668, which is greater than set $\mathrm{p}=\mathrm{0}, 05$, which indicates equality of dispersions;

- $\mathrm{df}$ - number of degrees of freedom, the value of which is used to define the table value of $\mathrm{t}$ test, which is compared to the calculated one, $\mathrm{df}=1198$;

- $t$-value $-t$-criterion value, equal to $t_{\text {emp. }}=-4.54801$, which is greater than $t_{\text {tabl. }}=1.960$, as the calculated value is compared to the table value by the module;

- p -t-criterion significance level, equal to o.0oooo6, which also confirms certainty and significance of calculated Student's t-test, as the set certainty level of $p=0.05$ is greater than the calculated one.

Based on obtained results, we can conclude that means differ significantly, as calculated Student's t-test is greater than the table one $(|-4,54801|>1,960)$. All results are statistically valid, which is why hypothesis o - social-pedagogical leisure activities system of formation of student youth's social activity facilitates the decrease of specific share of students with low level of formation of social activity and improves its development to medium and high levels, which confirms the effectiveness of the developed system - is accepted.

Using grouping and graphical visualization methods, a comparative diagram of the range of social activity formation levels of students in experimental (EG 1, EG 2) and control (CG 1, CG 2) groups was constructed according to results of diagnostic questioning methodologies after realizing the social-pedagogical leisure activities system of formation of student youth's social activity (figure 4).

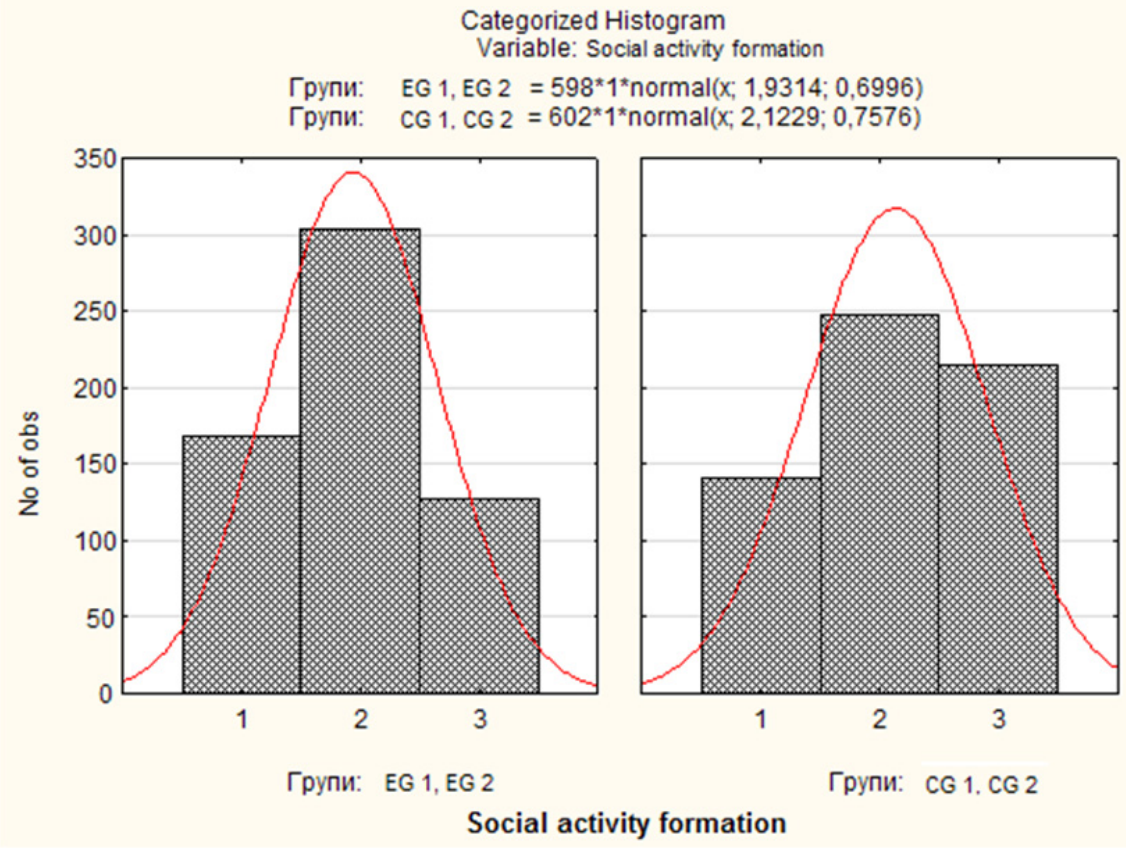

Figure 4. Categorized diagram of the range of formation of student youth's social activity in experimental (EG 1, EG 2) and control (CG 1, CG 2) groups

Categorized range diagram (figure 4) shows the variable distribution for experimental (EG 1, EG 2) and control groups, which are broken down into groups of formation of student youth's social activity 
by levels ( 1 - high, 2 - medium, 3 - low). Both graphs show that the level of formation of student youth's social activity in experimental groups is better than in control groups, which confirms the effectiveness of developed and implemented events of the social-pedagogical leisure activities system of formation of student youth's social activity.

\section{Conclusions}

Thanks to developed and implemented social-pedagogical leisure activities system of formation of student youth's social activity, as well as close cooperation with academic group curators and student self-government, using methods of observation, conversation and repeated diagnostics by selected methodologies, positive shifts in levels of formation of student youth's social activity were marked, thanks to organization of their leisure activities in terms of social-pedagogical approach. As such, level of formation of students' social activity in EG 1 (KhSAC) and EG 2 (SumSPU n.a. A. S. Makarenko) has increased by $30.26 \%$ and $30.31 \%$ respectively thanks to improvement of component indices (self-starter, social mobility social creativity) by all criteria (motivation-value, reflection-will, activity). Group curators have noted the usefulness and efficacy of joint extracurricular leisure events, which allowed to understand contemporary tendencies and likings of students, and for students - to exercise and implement initiatives, particularly by using new technologies. Among the most interesting forms of leisure practices students noted: the online-quest, creating virtual students forum in mobile apps, virtual methodological conference, debate evening, conducting virtual social promotional campaign, virtual leisure environment. Social-pedagogical approach, which is a basis for implementing leisure practices thanks to including students in social activity centers and spreading it beyond the limits of HEI, allowed to effectively realize the social-pedagogical leisure activities system for formation of student youth's social activity, which was proven in this research.

\section{References}

Aseeva, O.V. (2015). Virtualization of Youth Social Activity in Online Communities. Candidate's Thesis. Belgorod: BNRU.

Bilyk, O.M. (2018). Theory and Methods of Socialization of Foreign Students in the Educational and Cultural Environment of Higher Education. Doctor's thesis. Luhansk: KhNAC.

Bogdanova, I.M. (2008). Social Pedagogy: Textbook. Kyiv: Znannya.

Hanmurzina, R. R. (2013). Formation of Social Activity of Students in the Process of Cultural and Leisure Activities: Motivation and New Challenges. CPJ, 1 (96).

Hendrick, O.Yu. (2014). Development of Sociality of Students of Art Specialties by Means of Choreography. Candidate's thesis. Luhansk: KhNAC.

Kulinchenko, O.S. (2015). The Form of Social Activity of Students in the Minds of the Organisms of SelfDetermination of the Other Main Mortgage. Extended abstract of candidate's thesis. Kyiv: NPDU.

Maksimovska, N.O. (2015). Theoretical and Methodical Bases of Social and Pedagogical Activity with Student's Youth in the Field of Leisure. Doctor's thesis. Luhansk: KhNAC.

Maksimovsky, M.I. (2018). Development of Social Culture of Student Youth by Means of Animation Activity. Candidate's thesis. Luhansk: KhNAC.

Prokhorenko T.G. (2016). Socialization of Youth in the Information Society: Features and Risks. Bulletin of the National University "Yaroslav Mudryi National Law University", 2, 128-134.

Rasskazova, O.I. (2014). Theory and Practice of Pupils' Sociality Development in Terms of the Inclusive Education. Luhansk: KhNAC.

Shakirova, E.F. (2008). Comparison of the Severity of Characteristics of Students' Social Activity in a Teacher Training College. Psychological Science and Education, 5, 26-36.

Shakirova, E.F. (2010). Formation of Social Activity of Students of Teacher Training College in Extracurricular Activities. Candidate's thesis. Moscow: MCU.

Smuk, O., \&Kozubovsky, M. (2014). Social Problems of Modern Youth of Ukraine in the Conditions of Transformation of Political and Socio-Economic Systems. Scientific Bulletin of Uzhhorod National University, 30, 159-161. 
Tadaeva, A.V. (2016). Socio-Pedagogical Support of Socialization of Junior Schoolchildren in the Modern Information Space. Candidate's thesis. Luhansk: KhNAC.

Voronkova, V.G. (Ed.). (2017). Information Society in the World and Ukraine: Problems of Formation and Patterns of Development: A Collective Monograph. Zaporozhye: ZDIA.

World Declaration on Higher Education for the Twenty-First Century: Vision and Action and Frame-work For Priority Action for Change and Development in Higher Education, (1998). [Online] Available:https://unesdoc.unesco.org/ark:/48223/pfoooo141952 (May 6, 2020).

Zvereva, I.D. (1998). Socio-Pedagogical Work with Children and Youth in Ukraine: Theory and Practice. Kyiv. 